九州大学学術情報リポジトリ

Kyushu University Institutional Repository

\title{
Properties of Papers Sized with Rosin under Acidic to Alkaline Papermaking Conditions
}

Wu, Zonghua

Laboratory of Industrial Chemistry of Wood, Faculty of Agriculture, Kyushu University

Tanaka, Hiroo

Laboratory of Industrial Chemistry of Wood, Faculty of Agriculture, Kyushu University

https://doi.org/10.5109/24236

出版情報：九州大学大学院農学研究院紀要. 42 (3/4)，pp.483-490，1998-03. Kyushu University バージョン：

権利関係 : 


\title{
Properties of Papers Sized with Rosin under Acidic to Alkaline Papermaking Conditions
}

\author{
Zonghua Wu and Hiroo Tanaka
}

\author{
Laboratory of Industrial Chemistry of Wood, Faculty of Agriculture, \\ Kyushu University, Fukuoka 812-8581, Japan \\ (Received November 26, 1997 and accepted December 3, 1997)
}

\begin{abstract}
Effects of the new rosin sizing method with a rosin emulsion, alum and polyvinylamine (PVAm) on the properties of the sized papers were investigated in terms of basis weight, sizing degree, $\mathrm{pH}$ value, brightness and folding endurance of the papers. The MIT folding endurances of the sized papers were much larger than that of the control paper due to the use of PVAm in the sizing. The $\mathrm{pH}$ values of papers Nos. 1 to 5 sized at pHs 5 to 8 were in acidic region varying from $\mathrm{pH} 5.5$ to 5.8 , and the papers lost dramatically their brigthnesses and folding endurances. The $\mathrm{pH}$ values of papers Nos. 6 to 10 containing different amounts of $\mathrm{CaCO}_{3}$ varied from $\mathrm{pH} 7.9$ to 8.3 , and the papers retained their permanence well during the accelerated aging. These results illustrate that although the new sizing method was effective under neutral-alkaline papermaking conditions, the sized papers were acidic and exhibited poor permanence. The use of $\mathrm{CaCO}_{3}$ in the rosin sizing could make the sized papers alkaline so that the papers showed good permanence.
\end{abstract}

\section{INTRODUCTION}

Internal sizing in paper manufacture is an important process to provide paper and paperboard with resistance to liquid wetting, penetration and absorption. Rosin with alum has been a dominant sizing agent since 1807. Papers sized with rosin and alum, however, generally become yellow and brittle when they age. This has been a serious problem for the preservation of library materials (Luner, 1969; Roberson, 1976; Usuda, 1984; Oye, 1988). Previous studies have illustrated that paper acidity due to alum is one of major causes responsible for the deterioration of the papers (Dixson and Nelson, 1962; Kim et al., 1988; Lyne, 1995). Although alkaline sizing is a remedy to the problem, the alkaline sizing agents, for example alkyl ketene dimer (AKD) and alkenyl succinic anhydride (ASA), are expensive and difficult to deal with compared with rosin sizes. The use of familiar rosin sizes to papermaking under neutral-alkaline conditions has been studied by many investigators in the past decade (Biermann, 1992; Nakajima, 1993; Tahara et al., 1996).

In the previous papers (Wu and Tanaka, 1995; 1996; 1997), we reported that conventional rosin sizes with alum and polyamines exhibited effective sizing in the region from $\mathrm{pH} 4$ to 8 . Since alum is still used in the sizing, it is necessary to evaluate the effects of the new sizing method on properties of the sized papers. This paper deals with basis weight, sizing degree, $\mathrm{pH}$ value, brightness and folding endurance of the papers. The permanence of the papers, in addition, was investigated by means of accelerated aging carried out at $105^{\circ} \mathrm{C}, 0 \% \mathrm{RH}$ for 30 days. 


\section{MATERIALS AND METHODS}

\section{Materials}

A commercial bleached hardwood kraft pulp was used. The pulp was beaten to a Canadian Standard Freeness (CSF) of $410 \mathrm{ml}$ in a TAPPI (Technical Association of the Pulp and Paper Industry) standard beater. Polyvinylamine (PVAm ) was prepared based on the method (Tanaka and Senju, 1976). The average molecular weight of the PVAm was 320,000 (Wu and Tanaka, 1995). Alum $\left(\mathrm{Al}_{2}\left(\mathrm{SO}_{4}\right)_{3} \cdot 16 \sim 18 \mathrm{H}_{2} 0\right)$ was obtained from Tokyo Kasei Kogyo Co. Ltd.. The rosin emulsion size (RE) was kindly provided by the size maker.

\section{Preparation of rosin sized papers}

A pH value of an aqueous pulp slurry at consistency of $1.1 \%$ was adjusted to the desired pH. Alum (20 mg/g pulp), PVAm (1 mg/g pulp) and RE ( $5 \mathrm{mg} / \mathrm{g}$ pulp) were added to the slurry, sequentially, with stirring. Then the slurry was diluted with water previously adjusted to the desired $\mathrm{pH}$, and handsheets were formed according to TAPPI Test Method T205om-88. The wet sheets were pressed at $350 \mathrm{kPa}$ for $5 \mathrm{~min}$, and dried at $105^{\circ} \mathrm{C}$ for $10 \mathrm{~min}$. The dry sheets were conditioned at $20^{\circ} \mathrm{C}$ and $65 \% \mathrm{RH}$ for more than $12 \mathrm{~h}$. Sizing degrees were evaluated according to JIS P 8122.

When calcium carbonate was used, it was added to a pulp slurry before the other additives. The slurry was prepared and dilute with tap water ( $\mathrm{pH} 7.7)$.

\section{Procedure for accelerated aging of the sized papers}

Accelerated aging of the sized papers was carried out according to TAPPI Test Method T453om-89. The papers were heated in a convection oven at $105^{\circ} \mathrm{C}$. The samples were taken at desired times, and conditioned at $20{ }^{\circ} \mathrm{C}, 65 \mathrm{RH} \%$.

The MIT folding endurances under the tension of $50 \mathrm{kPa}$ and $\mathrm{pH}$ values of the samples were measured according to JIS P 8115 and JIS P 8133, respectively. The brightnesses of the samples were measured with a MINOLTA CR-200 photoelectric reflectance photometer.

\section{Quantitative analysis of rosin in the sized papers}

The quantity of sizing agents in the papers was determined by pyrolysis-gas chromatography (Py-GC) combined with on-line methylation (Yano et al., 1992; Ishida et $a l ., 1994)$. A vertical microfurnace-type pyrolyzer (Shimadzu PYR-4A) was directly attached to a gas chromatography (Shimadzu GC-17A) equipped with a flame ionization detector. About $500 \mu \mathrm{g}$ of the milled paper sample was exactly weighed using a platinum sample cup, and then $4 \mu \mathrm{L}$ of tetramethylammonium hydroxide (TMAH) was added to the

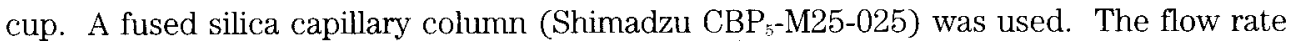
of carrier gas (He) was reduced from $50 \mathrm{~mL} / \mathrm{min}$ at the pyrolyzer to $1.0 \mathrm{~mL} / \mathrm{min}$ at the capillary column by means of a splitter. The column temperature was initially set at $80^{\circ} \mathrm{C}$, and then programmed up to $300^{\circ} \mathrm{C}$ at a rate of $5{ }^{\circ} \mathrm{C} / \mathrm{min}$. 


\section{RESULTS AND DISCUSSION}

\section{Properties of the papers sized with RE at different pHs}

Table 1 gives the properties of the papers sized with the rosin emulsion size (RE), PVAm and alum from $\mathrm{pH} 5$ to 8 . The basis weights of the papers (Nos. 1 to 5) increased from $61 \mathrm{~g} / \mathrm{m}^{2}$ at $\mathrm{pH} 5$ to $72 \mathrm{~g} / \mathrm{m}^{2}$ at $\mathrm{pH}$ 8. This may be explained by the fact that more fines in a pulp slurry can be retained in a sheet at neutral pHs because fibers in the slurry at higher pHs were more swollen.

Although the papers Nos. 1 to 5 were formed at $\mathrm{pH} 5.0$ to 8.0 , their $\mathrm{pH}$ values were in an acidic region from $\mathrm{pH} 5.2$ to 5.8. It was reported that the extractable acidity of a sheet is not a simple function of the stock $\mathrm{pH}$, and a aluminum sulfate solution remains sensibly constant over most of the range of neutralization (Reynolds and Linke, 1963). Since alum in a pulp slurry at pH 5.0-8.0 is mostly retained in a sheet (Aoki et al., 1995; Wang et al., 1997 ) and the papers Nos. 1 to 5 contained about $6.5 \%$ of water, the buffering effect of the alum retained in Nos. 1 to 5 may explain the small change in their $\mathrm{pH}$ values. The $\mathrm{pH}$ values of the papers containing $\mathrm{CaCO}_{3}$ (Nos. 6 to 10), however, were in a weak alkaline region from $\mathrm{pH} 7.9$ to 8.3 . The presence of small amount of $\mathrm{CaCO}_{3}(16 \mathrm{mg} / \mathrm{g}$ pulp) in No. 6 made the paper pH rise to 7.9 , compared with pH 5.2 to 5.8 of Nos. 1 to 5 . From the standpoint of paper preservation, a neutral-alkaline paper is desirable. The results described above illustrate that the use of $\mathrm{CaCO}_{3}$ in rosin sizing can make sized papers neutral-alkaline.

The sizing degrees of Nos. 1 to 10 covered the range from $42 \mathrm{~s}$ to $18 \mathrm{~s}$, illustrating that conventional rosin sizes with alum and PVAm exhibit effective sizing in a wide $\mathrm{pH}$ region

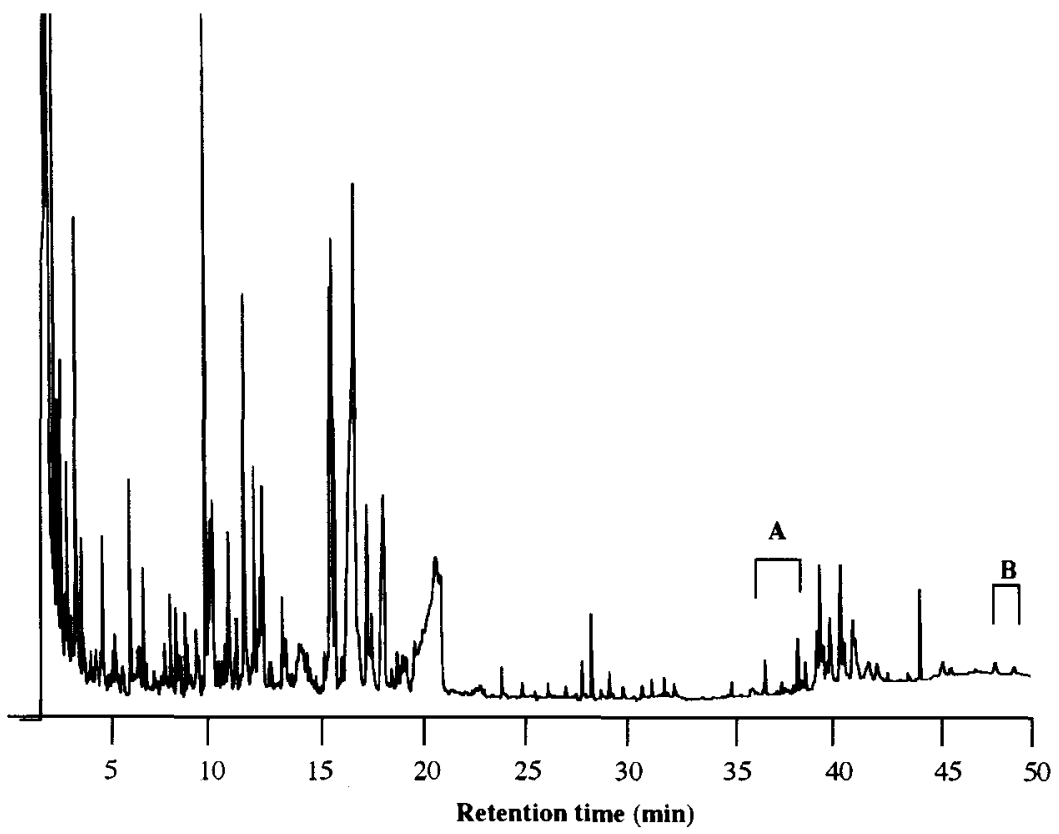

Fig. 1 The pyrogram of the rosin sized paper No. 1. 


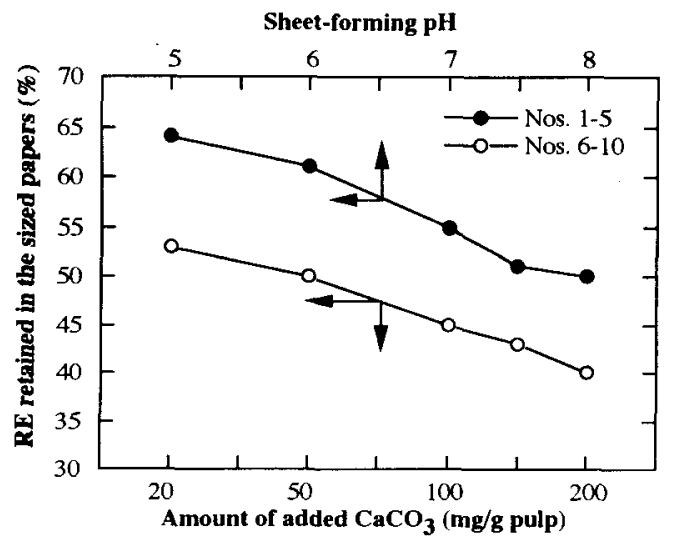

Fig. 2 Effect of sheet-forming $\mathrm{pH}$ and the amounts of added $\mathrm{CaCO}_{3}$ on the retention of rosin size (RE) in the sized papers.

(Wu and Tanaka, 1995; 1996; 1997). To clarify effects of the sheet-forming pHs on the sizing degrees of the papers, the amounts of RE retained in the papers were determined by Py-GC. Figure 1 shows the pyrogram of the paper No. 1. The peak A (retention time, 36 to $38 \mathrm{~min}$ ) and B (47-49 $\mathrm{min}$ ) are assigned for RE (Ishida et al., 1994; Wu and Tanaka, 1998). The RE retention decreased from $64 \%$ of No. 1 at pH 5 to $49 \%$ of No. 5 at pH 8 (Fig. 2). The sheet-forming $\mathrm{pHs}$ significantly influenced the RE retention. The comparison of the values in Table 1 and Fig. 2 shows that the decrease in the sizing degrees of Nos. 1 to 5 is in agreement with that in the RE retention. On the other hand, the increase in amounts of added $\mathrm{CaCO}_{3}$ from $20 \mathrm{mg} / \mathrm{g}$ pulp to $200 \mathrm{mg} / \mathrm{g}$ pulp reduced the RE retention from $53 \%$ of No. 6 to $40 \%$ of No. 10 . The sizing degrees (Table 1) decreased from $30 \mathrm{~s}$ of No. 6 to $18 \mathrm{~s}$ of No. 10. A higher sheet-forming $\mathrm{pH}$ and larger amount of added $\mathrm{CaCO}_{3}$ may result in a less $\mathrm{RE}$ retention and a smaller sizing degrees of the papers.

As shown in Table 1, the control sheet which was formed at $\mathrm{pH} 7.7$ was slightly brighter than the sheets Nos. 1 to 4 , and the brightness (96\%) of No. 1 was 2 point smaller than that (98\%) of No. 5. The comparison of the brightnesses and the RE retention shows that a larger $\mathrm{RE}$ retention is correlated with a smaller brightness, indicating that the sizing may cause a little brightness losses of the papers. The application of $\mathrm{CaCO}_{3}$ to the rosin sizing enhanced appreciably the brightnesses of Nos. 7 to 10. This is also a reason for rapid increase in use of calcium carbonate in papermaking.

Effects of the rosin sizing on mechanical properties of Nos. 1 to 10 was evaluated in terms of MIT folding endurance. The folding endurances of Nos. 1 to 5 were much larger than 42 folds of the control paper (Table 1). This may be attributed to the strengthen effect of PVAm and high molecular weight surfactant in RE on the folding endurances of the papers $(\mathrm{Wu})$. With increase of sheet-forming $\mathrm{pH}$ from 5 to 8 , the folding endurances of the sheets increased from 112 folds of No.1 to 195 folds of No. 5, due to the increase in their basis weights with increasing $\mathrm{pH}$. 
Table. 1 Properties of the papers sized with the rosin emulsion size at $\mathrm{pH} 5$ to $8^{\mathrm{a}}$.

\begin{tabular}{|c|c|c|c|c|c|c|c|}
\hline \multirow[b]{2}{*}{ No. } & \multirow[b]{2}{*}{$\begin{array}{l}\mathrm{pH} \text { of sheet- } \\
\text { forming }\end{array}$} & \multirow[b]{2}{*}{$\begin{array}{c}\mathrm{CaCO}_{3} \text { added } \\
\text { (mg/g pulp) }\end{array}$} & \multicolumn{5}{|c|}{ Paper properties } \\
\hline & & & $\begin{array}{l}\text { Basis weight } \\
\left(\mathrm{g} / \mathrm{m}^{2}\right)\end{array}$ & $\mathrm{pH}$ & $\begin{array}{c}\text { Sizing } \\
\text { degree } \\
\text { (s) }\end{array}$ & $\begin{array}{c}\text { Brightness }{ }^{\mathrm{b})} \\
(\%)\end{array}$ & $\begin{array}{l}\text { Folding } \\
\text { endurance } \\
\text { (folds) }\end{array}$ \\
\hline Control & 7.7 & - & 63 & 7.5 & - & 98 & 42 \\
\hline 1 & 5.0 & - & 61 & 5.2 & 42 & 96 & 112 \\
\hline 2 & 6.0 & - & 66 & 5.4 & 42 & 96 & 120 \\
\hline 3 & 7.0 & - & 66 & 5.5 & 39 & 96 & 161 \\
\hline 4 & 7.5 & - & 71 & 5.7 & 35 & 97 & 192 \\
\hline 5 & 8.0 & - & 72 & 5.8 & 31 & 98 & 195 \\
\hline 6 & 7.7 & 20 & 66 & 7.9 & 30 & 98 & 171 \\
\hline 7 & 7.7 & 50 & 68 & 8.1 & 25 & 98 & 112 \\
\hline 8 & 7.7 & 100 & 72 & 8.1 & 22 & 101 & 60 \\
\hline 9 & 7.7 & 150 & 74 & 8.3 & 19 & 102 & 29 \\
\hline 10 & 7.7 & 200 & 79 & 8.3 & 18 & 103 & 27 \\
\hline
\end{tabular}

a) The amounts of RE, alum and PVAm added in Nos. 1 to 5 were 5,20 and $1 \mathrm{mg} / \mathrm{g}$ pulp, respectively. The level of PVAm added in Nos. 6 to 10 was raised to $5 \mathrm{mg} / \mathrm{g}$ pulp.

b) Relative values of the brightnesses of the papers to that of a standard white plate.

\section{Deterioration of the sized papers during accelerated aging}

As described above, one of the main problem for rosin sizing is natural deterioration of the sized papers during storage. It is important to evaluate effects of a new sizing method on permanence of the sized papers because the permanence of paper has become an important property for many users to choose paper products. According to "Dictionary of Paper" (Michael, 1996), the permanence of paper refers to the retention of significant use properties, particularly folding endurance and color, over prolonged periods. The permanence of the papers Nos. 1 to 10 , therefore, is evaluated in terms of brightness and MIT folding endurance according to TAPPI Test Method T453om-89.

Upon heating, the papers suffered brightness losses to different extends as shown in Figs. 3 and 4. The papers Nos. 1 to 5 lost $5 \%$ of their brightnesses after being heated for 7 days, compared to $2 \%$ of the control paper. Significant differences in brightness can be seen among the papers heated for 30 days. The control paper remained $91 \%$ of its brightness, while No. 1 lost $14 \%$ of its brightness. The brightness losses in papers prepared under neutral pHs were smaller than those in the papers under the acidic conditions during the accelerated aging. The differences in the RE retention may be an explanation for the results. The rosin sizing caused brightness losses of the papers during the aging.

When $\mathrm{CaCO}_{3}$ is present in the papers, brightness losses of the papers is smaller (Fig. 4). After being heated for 30 days, No. 9 and No. 10 retained $92 \%$ and $93 \%$ of their brigthnesses, respectively. These values are larger than $91 \%$ of the control paper. It can be seen from Fig. 4 that the brightness losses decreased with the increases in amounts of $\mathrm{CaCO}_{3}$. This may be explained by the facts that rosin contents is lower in the papers 


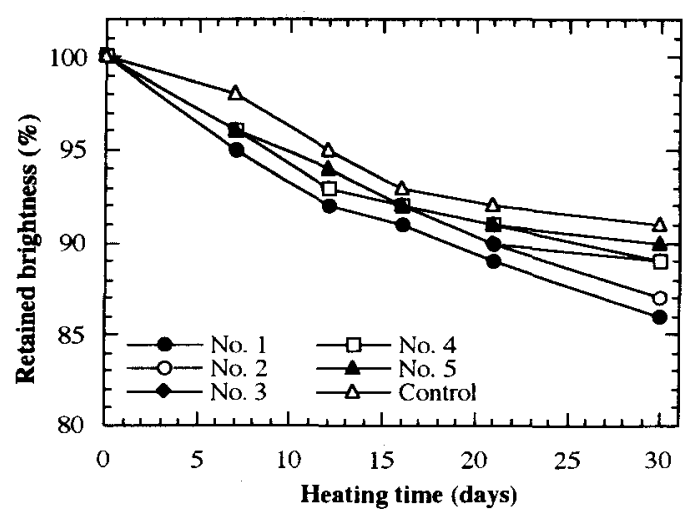

Fig. 3 Effect of sheet-forming $\mathrm{pH}$ on the brightnesses of the rosin sized papers during accelerated heating.

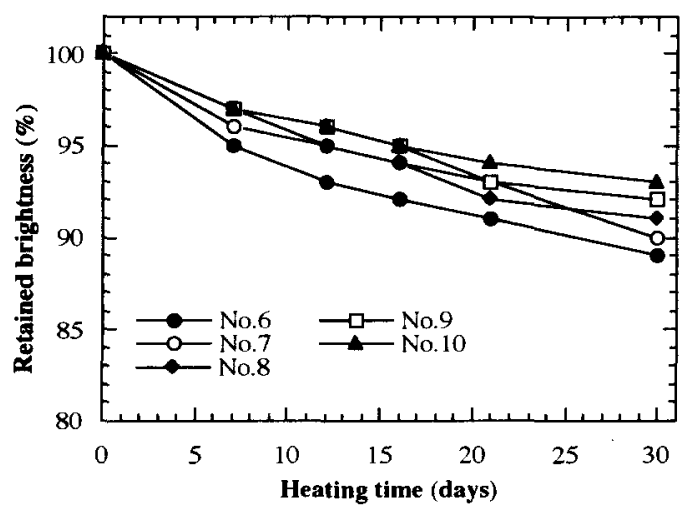

Fig. 4 Effect of the amounts of added $\mathrm{CaCO}_{3}$ on the brightnesses of the sized papers during accelerated aging.

containing more $\mathrm{CaCO}_{3}$, and that $\mathrm{CaCO}_{3}$ is stable during the heating.

Figure 5 shows effects of sheet-forming $\mathrm{pH}$ on the MIT folding endurances of the rosin sized papers Nos. 1 to 5 during the accelerated aging. Nos. 1 to 5 heated for 30 days lost half of their folding endurances, compared to $31 \%$ of the control paper. This may attributed to the acidities of the papers, illustrating that the rosin sizing of RE with alum and PVAm also caused significant losses in the folding endurances of the sized papers. As shown in Fig. 6, however, the rosin sized papers Nos. 6 to 10 retained their endurance 
well during the aging. After being heated for 30 day, No. 10 lost $30 \%$ of its endurance, compared to $31 \%$ of the control paper. This may be due to the fact that the $\mathrm{pH}$ values of Nos. 6 to 10 were in the neutral region.

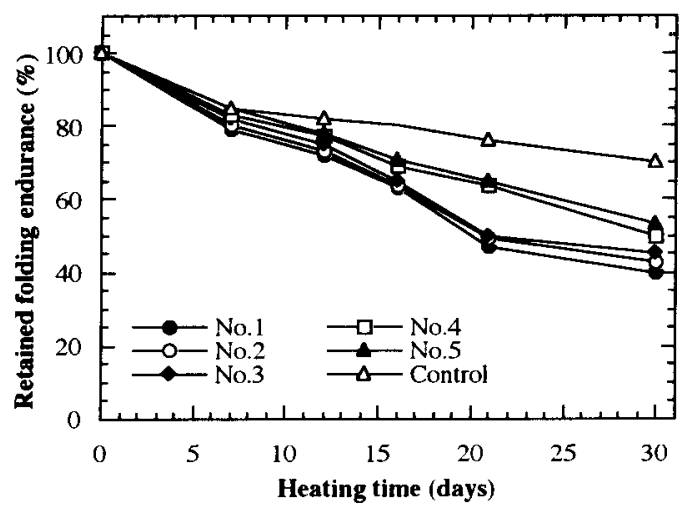

Fig. 5 Effect of sheet-forming $\mathrm{pH}$ on the MIT folding endurances of the rosin sized papers during the accelerated aging.

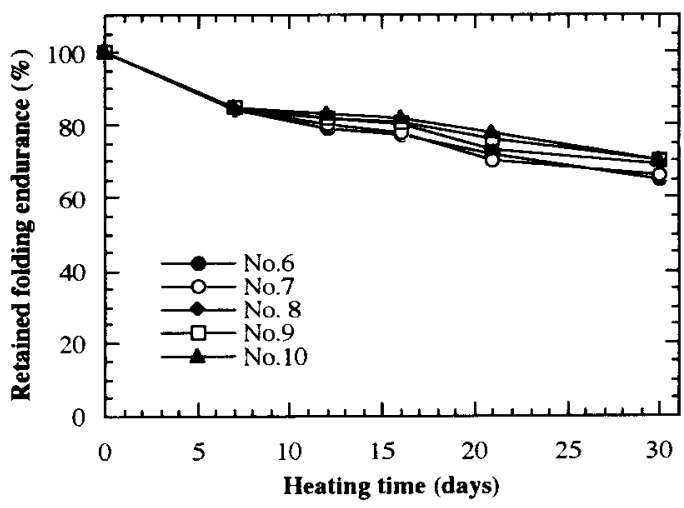

Fig. 6 Effect of the amounts of added $\mathrm{CaCO}_{3}$ on the MIT folding endurances of the rosin sized papers during accelerated aging. 


\section{REFERENCES}

Aoki, M., Ishigaki, H., Doki, H., and Igarashi, T. 1995 Aggregation behavior in pulp-alum-PAM systems. Japan Tappi, 49: 331-338

Biermann, C. J. 1992 Rosin sizing with polyamine mordants from $\mathrm{pH} 3$ to 10. Tappi J., 75 (5): 166-171

Dixson, H. P. and Nelson, J. C. 1962 An accelerated aging study of several writing papers. Tappi, 45: $753-760$

Ishida, Y., Ohtani, H., Kato, T., Tsuge, S. and Yano, T. 1994 Determination of rosin sizing agents in papers by pyrolysis-gas chromatography combined with on-line methylation, Tappi J., 77(3): 177-183

Kim, B. Y., Isogai, A., Onabe, F. and Usuda, M. 1988 Influence of UV treatments on paper properties. Japan Tappi, 42: 1165-1170

Luner, P. 1969 Paper permanence. Tappi, 52: 796-805

Lyne, M. B. 1995 The effect of $\mathrm{pH}$ on the permanence of LWC paper and fine paper made from recycled LWC. Tappi J., 78 (12): 138-144

Michael, K. 1996 "The Dictionary of Paper" TAPPI Press, p. 222

Nakajima, M. 1993 Rosin based and new material based neutral sizing agents. Japan Tappi, 47: 583593

Oye, R. 1988 Degradation of library materials and its preservation Mokuzai Gakkaishi, 34: 781-787

Reynolds, W. F. and Linke, W. F. 1963 The effect of alum and pH on sheet acidity, Tappi, 46: 410-415

Roberson, D. D. 1976 The evaluation of paper permanence and durability. Tappi, $\mathbf{5 9}$ (12): 63-69

Tahara, T. Matsushima, K. and Koguchi, O. 1996 The new neutral sizing agent. Japan Tappi, 50(2): 120-127

Tanaka, H. and Senju, R. 1976 Hofmann degradation of polyacrylamide. Kobunshi Ronbunshu, 33 (6): 309-316

Usuda, M. 1984 The current trend of book preservation and the mechanism of degradation of paper. Japan Tappi, 38: 48-57

Wang, F. Wu, Z.-h. and Tanaka, H 1997 Absorption mechanisms of aluminum on pulp fibers. Proceedings of the 4th Annual Meeting of Kyushu Branch in JapanWood Research Society, Miyazaki, pp 41-42

Wu, Z.-h. unpublished data

Wu, Z.-h. and Tanaka, H. 1995 Behaviors of polyvinylamines in neutral rosin sizing. Mokuzai Gakkaishi, 41: $911-916$

Wu, Z.-h. and Tanaka, H. 1996 Application of rosin amide to sizing under neutral papermaking conditions. Forest. Prod. chem. Ind, 16(3): 15-20

Wu, Z.-h. and Tanaka, H. 1997 Effects of polyamine structure on rosin sizing under neutral Papermaking Conditions. J. Apply. Polym. Sci., 65: 2159-2163

Wu, Z.-h. and Tanaka, H. 1998 Effects of papermaking additives on natural deterioration of printed wood-free papers. J. Wood Sci., 44(2): in press

Yano, T., Ohtani, H and Tsuge, S. 1992 Determination of neutral sizing agents in paper by pyrolysis-gas chromatography. Analyst, 117: 849-852 